\title{
GILBERTO BERGSTEIN
}

\section{OS LIMITES DO DEVER DE INFORMAÇÃO NA RELAÇÃO MÉDICO-PACIENTE E SUA PROVA}

\section{TESE DE DOUTORADO}

Orientadora: Professora Titular Teresa Ancona Lopez

FACULDADE DE DIREITO DA UNIVERSIDADE DE SÃO PAULO SÃO PAULO - 2012 


\section{RESUMO}

O presente trabalho construiu-se a partir dos novos paradigmas que permeiam a relação médico-paciente. Se o profissional não mais se encontra em uma posição de superioridade (ao menos do ponto de vista fático) em face de seu paciente, que por sua vez está mais sensível em virtude das transformações oriundas da sociedade de massa, o elemento informação ganhou contornos importantíssimos, inserindo-se no núcleo principal da prestação, ao lado dos cuidados relativos à saúde propriamente ditos.

Nesse contexto, foi proposta uma nova visão do dever de informar na relação médico-paciente, tratando a informação como uma obrigação autônoma, que gera de per se - em caso de ausência ou vício - responsabilização civil. A reparação, em tal perspectiva, surge a partir da violação do direito à liberdade: se a autodeterminação é um atributo da personalidade do paciente, a afronta a esse direito acarreta danos indenizáveis.

Os limites do dever de informar, assim, desempenham relevante papel, pois demarcam a tênue linha que distingue a informação viciada (que ensejará responsabilização civil) daquela transmitida diligentemente. Assim, o conteúdo e a extensão da informação foram abordados, confrontando-se aspectos subjetivos, objetivos e buscando uma solução ao mesmo tempo viável (do ponto de vista prático), jurídica e justa.

Como o trabalho trata essencialmente do dever de informar na relação médico-paciente e das consequências jurídicas derivadas do inadimplemento dessa obrigação, foram destrinchados todos os elementos que compõem esse complexo vínculo, passando por sua evolução histórica, pelos princípios, valores e direitos que permeiam e iluminam esta relação e, finalmente, pelos sujeitos que a compõem. Aspectos processuais atinentes à prova do cumprimento do dever de informação foram, ainda, examinados. Diversas questões polêmicas, tais como recusa de tratamento, direito a não saber, privilégio terapêutico, dentre outros, foram também debatidos.

Palavras-chave: relação médico-paciente - informação - liberdade - autonomia consentimento informado - responsabilidade civil. 


\begin{abstract}
This study is based on the new paradigms that permeate the doctor-patient relationship. If the medical professional no longer holds a superior position (at least from the factual point of view) vis a vis the patient who, on the other hand, is more aware to changes originating from doctor-patient relationship in the mass society, information availability has gained highly important contours, inserting itself into the core of services rendered, together with health care services themselves.

In this context, this study proposes a new vision of the duty to inform in a doctor-patient relationship, treating information as an autonomous obligation, that, per se, results in liability - in the case of its absence or flaws. The compensation, in such perspective, arises from breach of the right to autonomous choice: if self-determination is a characteristic of the patient's personality, the disrespect of this right results in damages subject to indemnification.
\end{abstract}

Therefore, the limits of the duty to inform perform a relevant role since they demarcate the fine line that distinguishes flawed information (that can incur liabilities) from that transmitted diligently. Thus, the contents and the extension of the information were addressed, comparing subjective and objective aspects and seeking a solution at the same time viable (from the practical viewpoint), legal and just.

Since this study essentially deals with the duty to inform in the doctorpatient relationship and of the legal consequences derived from noncompliance of this duty, all factors that compose this complex link were carefully examined, reviewing its historical evolution, the principles, values and rights that permeate and elucidate this relationship and, finally, the parties involved. Legal evidential procedures related to fulfillment of the duty to inform were also examined. Various controversial topics such as the refusal to undergo treatment, the right to not be informed, therapeutic privilege, among others, were also discussed.

Key words: doctor-patient relationship - information - freedom - autonomy - informed consent - liabiity 


\section{RIASSUNTO}

Lo scopo della presente tesi è stato costruito a partire dai nuovi paradigmi che permeano la relazione medico-paziente. Dato che il professionista non si trova più in grado di mettersi in rapporto di superiorità (almeno dal punto di vista dei fatti) nei confronti del paziente, che al suo turno si trova più suscettibile in virtù delle trasformazioni richieste dalla società di massa, l'elemento informazione ha preso una piega diversa e importante, inserendosi nel nucleo principale di prestazione di servizi a fianco delle cure riguardanti la ritenuta salute.

Nel presente contesto, si propone una nuova impostazione sul rapporto medico-paziente che tratta l'informazione come obbligo autonomo, che scaturisce de per $s e$ - in caso di assenza o vizio - responsabilizzazione civile. La riparazione, sotto tale prospettiva, deriva dalla violazione dei diritti di libertà; se l'autodeterminazione è un attributo della personalità del paziente, l'inosservanza del sopraddetto diritto apporta danni indennizzabili.

I limiti del dovere di informare, svolgono ruolo rilevante, poiché segna la tenera linea che distingue l'informazione trasmessa in modo viziato (che procura responsabilizzazione civile) da quella trasmessa in modo diligente. Pertanto, il contenuto e l'estensione dell'informazione sono stati avvicinati, raffrontando aspetti soggettivi, obiettivi e cercando una soluzione al contempo viabile (dal punto di vista pratico), giuridica e giusta.

Siccome l'elaborato tratta essenzialmente del dovere di informare il rapporto medico-paziente e delle conseguenze giuridiche derivate dall'inadempienza dell'obbligo, sono stati individuati gli elementi costituenti di questo complesso vincolo, nel percorso della sua evoluzione storica, dei suoi principi, suoi valori e suoi diritti che permeano e danno luce al sopraddetto rapporto e, finalmente, dei soggetti che lo compongono. Aspetti processuali concernenti alla prova dell'adempimento dei doveri d`informazione sono stati, tuttora, esaminati. Diverse questioni polemiche, così come il rifiuto di cura, il diritto a non sapere, il privilegio terapeutico, tra l'altro, sono stati dibattiti pure.

Parole-chiave: Rapporto medico-paziente - informazione - libertà - autonomia consentimento informato - responsabilità civile. 


\title{
INTRODUÇÃO
}

\begin{abstract}
"A autonomia exige que permitamos que uma pessoa detenha o controle de sua própria vida, mesmo quando comportar-se de um modo que, para ela própria, não estaria de modo algum de acordo com seus interesses.

[...] o valor da autonomia deriva da capacidade que protege: a capacidade de alguém expressar seu caráter - valores, compromissos, convicções e interesses críticos e experienciais - na vida que leva."l
\end{abstract}

A relação médico-paciente concebida na antiguidade e desenvolvida durante muitos séculos ${ }^{2}$, na qual se verificava um grande abismo entre os sujeitos envolvidos, hoje não mais existe. A figura do profissional "quase-deus" da qual irradiavam todas as decisões e comandos a respeito do destino do corpo, da saúde e da vida do paciente está, há muito, ultrapassada. O paternalismo que envolvia a posição do médico - enquanto único detentor dos elementos que delimitariam a terapêutica a ser eleita e o tratamento a ser ministrado - cedeu espaço ao surgimento do paciente sensível, ciente de seus "novos direitos”, efetivamente consagrados a partir da Constituição Federal e do Código Civil de 2002.

Os princípios estatuídos na Lei Maior, dentre os quais importa destacar a dignidade da pessoa humana, e os direitos de personalidade insculpidos no vigente Código Civil, como o é a liberdade, estão inexoravelmente vinculados, e perfazem o rol de valores que circundam todo o ordenamento jurídico aptos a possibilitar a realização da pessoa humana $^{3}$. Na relação médico-paciente hodierna, o elo que alinha a dignidade da pessoa humana com a liberdade é, inequivocamente, a informação.

O direito à informação do paciente - como resultado de uma construção doutrinária e jurisprudencial assertiva ${ }^{4}$ - o trouxe para o centro da relação, e lhe permitiu, a partir de tal perspectiva, conhecer o estado de sua saúde, o diagnóstico dos eventuais males

\footnotetext{
${ }^{1}$ DWORKIN, Ronald. Domínio da vida: aborto, eutanásia e liberdades individuais; tradução de Jefferson Luiz Camargo. São Paulo: Martins Fontes, 2003, p.318-319.

3 A professora Maria Celina Bodin de Moraes estabelece a relação entre a liberdade e a "realização existencial", contemplando ainda os princípios da dignidade e da solidariedade (MORAES, Maria Celina Bodin de. Na medida da pessoa humana: estudos de direito civil. Rio de Janeiro: Renovar, 2010, prefácio, sem indicação de número de página).

${ }^{4}$ Um acórdão da $5^{\text {a }}$ Câmara Civil do Tribunal de Justiça do Estado de São Paulo, referido por Pontes de Miranda e datado de $1^{\circ}$ de outubro de 1954 firmou o seguinte entendimento: "Em se tratando de médico, age ele com culpa e está obrigado a ressarcir o dano se, sem o consentimento espontâneo do cliente, o submete a tratamento do qual lhe advém sequelas danosas [...]" (in PONTES DE MIRANDA, F.C. Tratado de Direito Privado, Tomo 53. $2^{a}$ edição, Rio de Janeiro: Borsoi, 1966, p.436).
} 
que o acometem, os tratamentos possíveis e os riscos associados. O próximo passo será efetivação de sua autodeterminação: caberá ao paciente, receptor da informação, eleger o tratamento e sopesar os riscos a ele inerentes - de forma voluntária e livre.

O dever de informar prestado de forma completa e satisfatória, assim, possibilitará a contrapartida do paciente, traduzida por seu consentimento informado. A informação livre e esclarecida, fruto de um processo complexo ${ }^{5}$, se instrumentaliza mediante a formalização do chamado termo de consentimento livre e esclarecido, que traçará a linha divisória e a delimitação dos riscos que deverão ser suportados por cada uma das partes: médico e paciente ${ }^{6}$. Os fundamentos do dever de informar, nesse panorama, defluem de axiomas contemplados no sistema e de variadas legislações ${ }^{7}$. A relação médico-paciente, não se pode olvidar, é permeada pela confiança, cuja compreensão está vinculada às legitimas e razoáveis expectativas dos sujeitos de direito que a compõe.

Os deveres de lealdade e cooperação que devem nortear todas as relações jurídicas - traduzidos em sua essência pela boa-fé objetiva - aguçam e ampliam ainda mais o dever de informar na relação médico-paciente (aqui analisado tanto pela ótica do médico quanto pela do paciente). A informação, pois, corresponde a verdadeiro dever de conduta, que toma contornos relevantes e importantes nessa relação específica a ponto de ser tratada autonomamente, não com um dever acessório, mas como elemento principal.

\footnotetext{
${ }^{5}$ Nesse sentido, Ana Carolina Brochado Teixeira assinala que o "processo" que culmina na exteriorização da vontade do paciente suscita uma informação preventiva e sucessiva, de forma a carrear os dados impactantes à saúde do indivíduo. (TEIXEIRA, Ana Carolina Brochado. Saúde, corpo e autonomia privada. Rio de Janeiro: Renovar, 2010. p.380). A prestação da informação como um processo será detalhadamente abordada ao longo do presente trabalho.

${ }^{6}$ Destaca-se, uma vez mais, a lição de Ana Carolina Brochado, para quem: "O consentimento informado é essencial por duas razões: (i) para que o paciente possa participar ativamente do processo terapêutico, já que ele é o protagonista dos atos que têm ingerência sobre seu corpo e (ii) para legitimar a conduta do médico." (TEIXEIRA, Ana Carolina Brochado. Saúde ... cit., p.380).

7 Ricardo Luis Lorenzetti, ao analisar os fundamentos do dever de informar, indica: (a) fundamento constitucional (respeito à liberdade); (b) fundamento dogmático (o ato jurídico deve ser voluntário e, para que exista voluntariedade, deve haver discernimento e intenção) e (c) fundamentos legais (Código de Defesa do Consumidor, Código Civil, Código de Ética Médica) (LORENZETTI, Ricardo Luis. Responsabilidad Civil de los Médicos, Tomo I, Buenos Aires: Rubinzal - Culzoni, 1997, p.203).
} 
Fixadas tais premissas básicas, o objetivo precípuo desse trabalho é demonstrar que a informação é o fator propulsor da liberdade de todo e qualquer paciente a respeito das questões que envolvem o seu corpo, saúde e vida; não por outro motivo, a informação será tratada como elemento principal da relação médico-paciente e, portanto, como causa autônoma de responsabilização civil (na hipótese de sua ausência ou de sua prestação viciada). Para o delineamento das discussões propostas, será traçado o seguinte percurso:

(i) No primeiro capítulo, a evolução da relação médico-paciente será destrinchada - do paternalismo à autonomia. Serão abordados aspectos como a natureza jurídica da relação médico-paciente e as obrigações e regras de responsabilidade daí advindas. Por fim, a relação médico-paciente será examinada sob a ótica dos direitos fundamentais a ela inerentes (dignidade da pessoa humana, saúde, solidariedade e liberdade);

(ii) No capítulo II, aspectos como a confiança e boa-fé objetiva serão largamente desenvolvidos. Será analisada a tríplice função da boa-fé objetiva e sua integração na relação médico-paciente, que encerra os deveres de cuidado (segurança) e lealdade (cooperação) que por sua vez são fundamentos do dever de informar;

(iii) Já no capítulo III, introduzir-se-á a figura da informação como fundamento para a autodeterminação do paciente. Após, será abordado o conteúdo da informação (diagnóstico, prognóstico, alternativas de tratamento e riscos) e alguns elementos que podem alterar significativamente a sua transmissão (tais como urgência ou novidade do tratamento), para, em seguida, examinar-se-á individual e detalhadamente os sujeitos do dever de informar e, por fim, no desfecho do capítulo, serão contemplados os meios de transmissão da informação;

(iv) O capítulo IV tratará dos limites do dever de informar. Serão abordados assuntos polêmicos como o direito de não receber informação e o privilégio terapêutico. $\mathrm{O}$ excesso de informação como causa de prejuízo à autonomia do paciente e os aspectos quantitativos e qualitativos da informação 
em relação à capacidade de assimilação do paciente também serão avaliados. O último item abordará uma das questões mais complexas do presente trabalho: o efetivo limite da informação - até que ponto o médico deve ir? Qual a linha certamente tênue - que traça a fronteira entre a boa (diligente) e a deficiente (negligente) informação. Critérios objetivos e subjetivos serão confrontados e suplantados com vistas a uma tentativa de solucionar o problema;

(v) No capítulo V, abordar-se-á a capacidade para consentir com o enfrentamento da condição dos adultos incapazes e dos menores. As questões controvertidas relativas ao direito de recusar tratamento e às declarações antecipadas de vontade serão desenvolvidas. A seguir serão abordados os casos nos quais se exige o consentimento expresso, o seu tempo, a sua presunção e, por fim, a sua revogação.

(vi) Os meios de prova da informação serão examinados no capítulo VI. Será tratada a questão da validade do termo de consentimento informado e da possibilidade da inversão do onus probandi em razão da dificuldade que terá o paciente de fazer prova negativa (no sentido de que não foi informado) e segundo os dispositivos previstos no Código de Defesa do Consumidor - que permeia, não sozinho, mas em diálogo com outros diplomas legais -, a relação médico-paciente;

(vii) Derradeiramente, no capítulo VII, propor-se-á uma nova visão do dever de informar, não mais como um elemento acessório na relação médicopaciente, e sim como obrigação autônoma, cujo inadimplemento (informação não prestada ou transmitida de forma viciada) enseja, de per se, responsabilização civil. Os argumentos propostos serão desenvolvidos em conformidade com entendimentos doutrinários e jurisprudenciais.

Se o exercício da liberdade individual situa-se numa perspectiva de privacidade, intimidade e exercício da vida privada e o seu significado está relacionado a "poder realizar" sem interferências de qualquer gênero, ou, nas palavras precisas de Maria Celina Bodin de Moraes, concretizar o próprio projeto de vida da forma como melhor 
convier $^{8}$, a informação, no âmbito da relação médico-paciente, é o verdadeiro "motor" da autodeterminação desse paciente e, como tal, deve constituir uma obrigação autônoma, porquanto tão relevante e importante como a prestação tida classicamente como principal (cuidados de saúde).

Esses serão os nortes que, com firmeza, conduzirão os caminhos a serem trilhados no presente trabalho.

\footnotetext{
${ }^{8}$ MORAES, Maria Celina Bodin de. Na medida... cit., p.108.
} 


\section{CONCLUSÃO}

Durante o caminho percorrido entre pesquisa, desenvolvimento e escrita da presente tese, buscou-se demonstrar o efetivo valor dos elementos liberdade, autonomia e informação - e, sobretudo, das importantes consequiências positivas que podem advir de sua correta observância e valoração.

A visão nuclear que este trabalho procurou sustentar, portanto, vai ao encontro das necessidades de proteção de direitos básicos, fundamentais para o bom desenvolvimento da personalidade dos indivíduos - valores nucleares que foram, de alguma forma, negligenciados pelos movimentos pendulares da sociedade e que, ao longo das últimas décadas, foram novamente trazidos à boca de cena das relações sociais.

Não seria possível alcançar esse objetivo sem que fosse feita uma breve análise histórica da relação entre médicos e pacientes, demonstrando-se, sobretudo, a dessacralização a que ela vem se submetendo ao longo das últimas décadas. O desnível outrora considerado natural, por meio do qual o profissional usava seu conhecimento para 'salvar' o doente do modo que bem entendesse, muitas vezes sem nem mesmo sequer consultá-lo, já não mais existe.

O médico já não mais é aquele ser inatingível, senhor absoluto da saúde e da vida de seu paciente, à quem se devia obediência cega. Ele agora deve ter a capacidade de efetivamente ouvir seu paciente, compartilhar suas angústias e propor caminhos, alternativas; ainda defendendo seus pontos de vista, mas com a capacidade de absorver eventual negativa do paciente e lhe propor algo diverso ou acatá-la.

Entretanto a História guardou as mais radicais mudanças para o papel do paciente: foi ele retirado de sua 'zona de conforto' (em que se resignava a aceitar soluções ditadas pelo profissional médico), e elevado também à categoria de protagonista desta relação. Um protagonista que tenta verdadeiramente entender a situação na qual se vê mergulhado - áreas pedregosas que as doenças, infelizmente, carregam para dentro da vida dos indivíduos - e, dessa forma, assumir o controle dela, decidindo ele próprio os rumos que quer ver adotados para a sua saúde, para o seu corpo, para sua vida, enfim.

Decidir. Escolher. E, mais do que isso: assumir inteiramente as consequiências desse ato. Pode-se dizer, sem medo de errar, que são esses os principais ônus e bônus proporcionados pela liberdade. É Brunello Stancioli quem bem define essa situação, ao comentar sobre renúncia ao exercício dos direitos de personalidade; "Essa escolha, embora individual, só é possível numa comunidade de pessoas em que todos se reconheçam iguais na potencialidade de escolher (autonomia) face aos outros (alteridade) e a sua própria noção de vida boa (dignidade)". 9

Concluiu-se, assim, que a saúde é direito de personalidade a ser exercido pelas pessoas como desdobramento direto do direito de liberdade, de controle sobre o próprio corpo ou de 'governo corporal' - expressão utilizada por Ana Carolina Brochado

\footnotetext{
${ }^{9}$ STANCIOLLI, Brunello. Renúncia ao exercício ... cit., p.124.
} 
Teixeira - sendo a autonomia instrumento apto à consagração da dignidade de cada indivíduo, paciente e/ou médico, dos seres humanos, enfim.

Viu-se também que o consentimento válido emitido pelo paciente consiste em nada mais que a contrapartida à informação prestada de maneira clara, compreensível (informação com qualidade) e completa. Assim, o holofote que anteriormente projetava sua luz unicamente sobre o médico, agora ilumina a ambos, posicionando o paciente no centro do palco, de modo que ele possa bem ver e analisar suas opções, e, por conseguinte, legitimamente exercer a soberania sobre o próprio corpo, em momento especial, em que se encontra fragilizado pela doença.

Concluiu-se também que a informação deve ser qualitativamente modulada para que diferentes pacientes tenham iguais possibilidades decisórias sobre as questões atinentes à sua saúde. Propôs-se, assim, que nesta relação deve-se olhar para o paciente em concreto, e não para um padrão 'médio', standart criado pelo Direito e adequado para outros tipos de relações jurídicas, mas não para a que se estudou. Foram também analisados uma série de critérios que devem ser utilizados como uma matriz matemática (todos juntos e coordenados) para quantificar-se a informação a ser transmitida, defendendo-se, inclusive, o direito do paciente a não receber qualquer informação, se assim lhe convier.

Os limites do dever de informação também foram analisados, por meio de uma visão panorâmica de vários ordenamentos que possuem legislações específicas sobre os direitos do paciente, verificando-se que a questão mais controversa é que cuida dos riscos envolvidos nos procedimentos ou tratamentos. Concluiu-se, assim, que devem ser objeto de informação os riscos previsíveis, típicos e frequentes relacionados aos cuidados de saúde que serão dispensados ao paciente, sem, contudo, deixar de lado aqueles menos frequentes, mas que possam causar graves danos ao paciente. Concluiu-se, também, que devem ser considerados os critérios subjetivos de cada paciente, e a própria natureza dos cuidados (medicina curativa versus satisfativa, na qual a informação deverá ser exaustiva), reforçando-se a noção de importância da análise casuística para a matéria estudada.

Discorreu-se sobre as regras gerais e critérios para que o consentimento do paciente seja válido, com realce para o fato de que ele deve ser compreendido como processo dinâmico, não instantâneo, importando valorizar-se o tempo para o amadurecimento das decisões do paciente. Destacou-se também a possibilidade de que o paciente poderá a qualquer momento, de modo igualmente livre, revogar o seu consentimento, devendo o médico precaver-se e requisitá-lo por escrito, a fim de instrumentalizar sua defesa em eventual processo judicial no qual venha a ser demandado.

Discutiram-se também os casos de incapacidade. Em especial, o caso da autonomia dos menores de idade (chamados de 'menores maduros') para consentir, propôs-se a utilização do regramento já existente no ECA relativo à guarda do menor e sua extensão para os casos relativos ao consentimento. Sustentou-se, desse modo, que o menor deveria ter sua opinião levada em conta para o fim de consentir ou não no tratamento médico que lhe é proposto. Concluiu-se também que os relativamente incapazes (a partir de 16 anos) deveriam poder tomar - autonomamente - decisões relativas à sua saúde (exceção feita aos casos que envolvem risco grave), em cotejo com outras possibilidades já previstas no próprio Código Civil brasileiro, observados seus níveis de maturidade e compreensão. Assim a proposta foi a de utilização de critério mais dinâmico, 
multifacetado; em detrimento do critério estático da idade cronológica, preservando e focando com mais vigor o melhor interesse do jovem.

Foram a seguir analisadas as questões tormentosas relativas à produção da prova do consentimento, concluiu-se que, na maior parte dos casos, a forma verbal é a mais corriqueira, sendo dispensada - no mais das vezes - a forma escrita para instrumentalização do consentimento. Deve-se ter em mente, todavia, que tal 'oralidade' não dispensa o correto preenchimento de ficha clínica e prontuário por parte dos profissionais, eis que $(i)$ serão elementos fundamentais na composição de uma consistente defesa judicial ou extrajudicial e, (ii) a contrario sensu o seu preenchimento de modo ilegível ou incompleto gerará contra o médico uma presunção de culpa pela negligência no tratamento das informações do paciente.

Propôs-se, também, critérios orientadores nos quais o consentimento por escrito se faz necessário: $(i)$ os procedimentos que retiram a consciência do paciente através de anestesia, (ii) aqueles invasivos (mesmo os minimante invasivos, como é o caso das endoscopias) e (iii) os que oferecem um maior nível de risco para a saúde do paciente.

Outra questão que mereceu destaque foi aquela do ônus da produção da prova. Após analisarem-se diversos ordenamentos, traçou-se a linha comum a todos eles: sua inversão tendo por base a teoria das cargas dinâmicas probatórias, que impõe o dever de provar à parte que se encontra em melhores condições de fazê-lo - o médico - havendo, no ordenamento pátrio artigo de lei expresso nesse sentido (CDC, artigo $6^{\circ}$, inciso VIII) e lembrando-se que há - nesses casos - uma presunção em favor do paciente, originada justamente de sua hipossuficiência técnica. Concluiu-se, ademais, que imputar esse ônus ao paciente seria obrigá-lo a produzir verdadeira probatio diabolica de que não foi informado (ou de que não foi suficientemente informado).

Como visto, a relação médico-paciente envolve o valor fundamental liberdade. $\mathrm{O}$ homem deve ser livre para decidir acerca de seu corpo, de sua saúde, de sua vida, desde que tais decisões não extrapolem os limites da sua própria pessoa. Esse exercício de liberdade jamais será possível sem informação. E ser livre é, na verdade, ter alcance a todas as informações necessárias para se fazer uma escolha própria, autêntica, íntegra e independente de injunções alheias. É também ela que promove o reequilíbrio das posições do médico e paciente.

Enfim, investigou-se a questão fulcral quanto à natureza do dever de informar na relação médico-paciente, concluindo ser ele autônomo, capaz de gerar responsabilização do médico independentemente de haver ou não dano decorrente da prestação relacionada ao cuidado de saúde - tradicionalmente entendida como "principal" no âmbito desta relação. Com efeito, consiste a relação médico-paciente num verdadeiro feixe obrigacional, que encerra inúmeros deveres recíprocos de conduta aos quais as partes estão sujeitas e que vão muito além da prestação tradicionalmente referida como 'principal' (ligada ao próprio objetivo de diagnóstico e/ou cura do paciente). Assim, dada a natureza da relação e dos bens nela envolvidos (saúde, integridade física, vida), assume a informação caráter fundamental, consistindo a pedra de toque, o elemento decisivo capaz de fazer com que esta relação se desenvolva legitimamente.

Nesse sentido o descumprimento do dever de obter consentimento informado ensejará a obtenção de ressarcimento pelo paciente e que tal inadimplemento é 
"causa autônoma de culpa, reconhecida como uma agressão à liberdade e aos direitos da personalidade do paciente e, por si só, também capaz de gerar pretensão distinta à obtenção de uma indenização". ${ }^{10}$

Os Tribunais cujas jurisprudências foram estudadas, aliás, já reconhecem que a infração ao dever de informação constitui dano autônomo e indenizável. Entendem, porém, que também há necessidade de que ocorra simultaneamente a concretização de riscos não informados - com o que não se concorda, tal como acima mencionado.

Com efeito, demonstrou-se que a infração ao dever de informação causa um dano, um dano de natureza moral decorrente da infração das garantias de informação e seu posterior consentimento. Abraçou-se de forma convicta a ideia de que esse dano deve ser indenizável de per se por causar violação a bem especialmente protegido pelo Direito: a autonomia do paciente (sua autodeterminação informativa) como corolário da dignidade da pessoa humana e do rol dos direitos da personalidade (saúde, vida e liberdade), independentemente de danos físicos ocorridos ou não, e que devem ser valorados, por conseguinte, individual e separadamente.

\footnotetext{
${ }^{10}$ SCAFF, Fernando Campos. Direito à saúde ... cit., p.98.
} 


\section{BIBLIOGRAFIA}

AGUIAR JÚNIOR, Ruy Rosado de. Responsabilidade civil do médico, in Direito \& Medicina, Coord.: TEIXEIRA, Sálvio de Figueiredo. Belo Horizonte: Del Rey, 2000.

AGUIRRE, João Ricardo Brandão. Responsabilidade e informação: efeitos jurídicos das informações, conselhos e recomendações entre particulares. São Paulo: Revista dos Tribunais, 2011.

AMARAL, Francisco. Direito civil: introdução. $7^{\mathrm{a}}$ edição, Rio de Janeiro: Renovar, 2008.

ANTUNES VARELA, João de Matos. Das obrigações em geral. 10a edição, Coimbra: Almedina, 2005.

ARAUJO, Valter Shuenquener de. O princípio da proteção da confiança. Rio de janeiro: Impetus, 2009.

AZEVEDO, Antonio Junqueira de. Crítica ao Personalismo Ético da Constituição da República e do Código Civil. Em favor de uma ética biocêntrica, in Princípios do novo código civil brasileiro e outros temas, homenagem a Tullio Ascarelli. São Paulo: Quartier Latin, 2008.

. Estudos e pareceres de direito privado. São Paulo: Saraiva, 2004.

2002.

. Negócio Jurídico: existência, validade e eficácia. $4^{\mathrm{a}}$ edição, São Paulo: Saraiva,

BARBOZA, Heloisa Helena. A autonomia da vontade e a relação médico-paciente no Brasil, in Lex Medicinae, revista portuguesa de direito da saúde, ano $1, \mathrm{n}^{\circ} 2$, julho/dezembro 2004.

BARRY, Brian. Justice as impartiality. Oxford: Clarendon Press, 1999.

BARROSO, Luís Roberto. Legitimidade da recusa de transfusão de sangue por testemunhas de Jeová. Dignidade humana, liberdade religiosa e escolhas existenciais. Parecer emitido a pedido da Procuradoria Geral do Estado do Rio de Janeiro, 2010.

BEAUCHAMP Tom L. et CHILDRESS, James F. Principles of biomedical Ethics. $5^{\mathrm{a}}$ edição, New York: Oxford University Press, 2001.

BELDARRAIM, Javier Larena. La carga de la prueba en el processo civil por responsabilidad médica, in Los avances del derecho ante los avances de la medicina, coord.: GIL-DELGADO, Maria Reyes Corripio et COPO, Abel B. Veiga. Navarra: Aranzadi, 2008.

BITTAR, Carlos Alberto. Os direitos da personalidade. $7^{\mathrm{a}}$ edição, São Paulo: Forense Universitária, 2004. 
BONAVIDES, Paulo. Curso de Direito Constitucional. 24a edição, São Paulo: Malheiros, 2009.

BUERES, Alberto J. Responsabilidad civil de los médicos. $3^{\mathrm{a}}$ edição, Buenos Aires: Hammurabi, 2006.

BUERGO, Bianca Mendoza. Autonomía personal y decisiones médicas: Cuestiones éticas y jurídicas. Cizur Menor: Thomson Reuters, 2010.

CALVO COSTA, Carlos A. Daños ocasionados por la prestación médico-asistencial. Buenos Aires: Hammurabi, 2007.

CANARIS, Claus-Wilhelm. Direito fundamentais e direito privado, tradução de Ingo Wolfgang Sarlet e Paulo Mota Pinto. Coimbra: Almedina, 2006.

. Pensamento sistemático e conceito de sistema na ciência do direito, introdução e tradução de António Menezes Cordeiro, $2^{\text {a }}$ edição. Lisboa: Fundação Calouste Gulbenkian, 1996.

1991.

et MOREIRA, Vital. Fundamentos da Constituição. Coimbra: Coimbra Editora,

CARNEIRO DA FRADA, Manuel António de Castro Portugal. Teoria da confiança e responsabilidade civil. Coimbra: Almedina, 2004.

CARPES, Artur. Ônus dinâmico da prova. Porto Alegre: Livraria do Advogado, 2010.

CASTILlO, Manuel Alonso Olea Fernando Fanego. Comentario a la ley 41/2002, de 14 de noviembre, básica reguladora de la autonomía del paciente y de derechos y obligaciones en materia de información y documentación clínica. Madrid: Civitas, 2003.

CAVALIERI FILHO, Sergio. Programa de responsabilidade civil. $7^{a}$ edição, São Paulo: Atlas, 2007.

COMPARATO, Fábio Konder. A afirmação histórica dos direitos humanos. $6^{\text {a }}$ edição, São Paulo: Saraiva, 2008.

CORDEIRO, António Manuel da Rocha e Menezes. Vide MENEZES CORDEIRO.

CORRÊA, Adriana Espíndola. Consentimento Livre e Esclarecido- O Corpo Objeto de Relações Jurídicas. São José: Conceito Editorial, 2010.

CORTÉS, Julio César Galán. Responsabilidad Civil Médica. $2^{\mathrm{a}}$ edição, Navarra: Thomson Civitas, 2007.

Responsabilidad médica y consentimiento informado. Madri: Civitas, 2001.

COUTO E SILVA, Clóvis V. do. A obrigação como processo. Rio de Janeiro: Editora FGV, 2009. 
CUMPLIDO. Manuel J. Consentimiento informado. Córdoba: Editorial Mediterránea, 2005.

DALLARI, Dalmo de Abreu. Direito à vida e a liberdade para morrer, in Pessoa humana e direito, Coord.: CAMPOS, Diogo Leite de et CHINELLATO, Silmara Juny de Abreu. Coimbra: Almedina, 2009.

DELMANTO, Celso. Código Penal comentado. $3^{\text {a }}$ edição, Rio de Janeiro: Renovar, 1991.

DE PLÁCIDO E SILVA. Vocabulário jurídico. $18^{\mathrm{a}}$ edição, atualizada por Nagin Slaibi Filho e Geraldo Magela Alves. Rio de Janeiro: Forense, 2001.

DIAS, José de Aguiar. Da responsabilidade civil. $6^{a}$ edição, volumes I e II, Rio de Janeiro: Forense, 1979.

DIAS, Lúcia Ancona Lopes de Magalhães. Publicidade e direito. São Paulo: Revista dos Tribunais, 2010.

DWORKIN, Ronald, Domínio da vida: aborto, eutanasia e liberdades individuais, tradução de Jefferson Luiz Camargo. São Paulo: Martins Fontes, 2003.

Levando os direitos a sério. São Paulo: Martins Fontes, 2002.

FABIAN, Christoph. O dever de informar no direito civil. São Paulo: Revista dos Tribunais, 2002.

Fidúcia: Negócios fiduciários e relações externas. Porto Alegre: Sergio Antonio fabris, 2007.

FACHIN, Luiz Edson et alii. O "aggionarmento" do direito civil e confiança negocial, in Repensando fundamentos do direito civil brasileiro contemporâneo. Rio de Janeiro: Renovar, 1998.

FERRAZ, Octávio Luiz Motta. Responsabilidade civil da atividade médica no Código de defesa do consumidor. Rio de Janeiro: Elsevier, 2009.

FRANZONI, Massimo. Tratatto della responsabilità civile - Tomo I - L'illecito. $2^{\text {a }}$ edição, Milano: Giuffrè, 2010.

GALÁN CORTÉS, Julio César. Vide CORTÉS, Julio César Galán.

GALEA, Felipe Evaristo dos Santos. Confiança do Consumidor na sociedade de risco massificada, in Revista de Direito Privado (RDPriv), Ano 12, Vol. 47, São Paulo: Revista dos Tribunais, 2011.

GARAY, Oscar E. Derechos fundamentales de los pacientes. Buenos Aires: Ad-Hoc, 2003. 
GARCIA, André Almeida. Prova e responsabilidade médica, in Provas: aspectos atuais do direito probatório, coord.: NEVES, Daniel Amorim Assumpção. Rio de Janeiro: Forense et São Paulo: Método. 2009.

GODINHO. Robson Renault. A distribuição do ônus da prova e a constituição, in Provas: Aspectos Atuais do Direito Probatório. Coord.: NEVES, Daniel Amorim Assumpção. Rio de Janeiro: Forense et São Paulo: Método, 2009.

GODOY, Claudio Luiz Bueno de. Função social do contrato. São Paulo: Saraiva, 2004.

- Responsabilidade pelo fato do produto e do serviço, in Responsabilidade civil nas relações de consumo, coord.: SILVA, Regina Beatriz Tavares da. São Paulo: Saraiva, 2009.

GOMES, Orlando. Introdução ao Direito Civil. Revista, atualizada e aumentada, de acordo com o Código Civil de 2002, por Edvaldo Brito e Reginalda Paranhos de Brito. 19a edição. Rio de Janeiro: Forense, 2008.

. Contratos, atualizado por Antonio Junqueira de Azevedo e Francisco Paulo de Crescenzo Marino. 26 edição, Rio de Janeiro: Forense, 2008.

GONÇALVES, Carlos Roberto, Responsabilidade Civil. $8^{\text {a }}$ edição, São Paulo: Saraiva, 2003.

GRINOVER, Ada Pellegrini. et alii. Código Brasileiro de defesa do consumidor comentado pelos autores do anteprojeto. 10 edição, Rio de Janeiro: Forense, 2011.

GRISSO, Thomas et APPELBAUM, Paul S.. Assessing competence to consent to treatment. New York: Oxford University Press, 1998.

GRUBB, Andrew. Principles of medical law. $2^{\mathrm{a}}$ edição, New York: Oxford University Press, 2004.

HABERMAS, Jürgen. Between facts and norms: contributions to a discourse Theory of Law and Democracy. Cambridge/Massachusetts: The MIT Press, 1996.

HOBBES, Thomas. Leviatã ou matéria, forma e poder de um estado eclesiástico e civil. São Paulo: Nova Cultural, 1997.

HIGHTON, Elena I. et WIERZBA, Sandra M. La relación médico-paciente: el consentimiento informado. $2^{\text {a }}$ edição, Buenos Aires: Ad-hoc, 2003.

ITURRASPE, Jorge Mosset et PIEDECASAS, Miguel A. Derechos del Paciente: Doctrina - Jurisprudencia. Santa Fe: Rubinzal-Culzoni, 2011.

Responsabilidad por daños, tomo VIII: responsabilidad de los profesionales. Santa Fe: Rubinzal-Culzoni, 2004.

KANT, Emanuel. Fundamentação da metafísica dos costumes, in Kant Political Writings. Cambridge: Cambridge University Press, 1997. 
KFOURI NETO, Miguel. Culpa médica e ônus da prova. São Paulo: Revista dos Tribunais, 2002.

Tribunais, 2010.

Responsabilidade civil do médico. $7^{\text {a }}$ edição, São Paulo: Revista dos

KRAUT, Alfredo J. Responsabilidad civil de los psiquiatras en el contexto de la prática médica. Buenos Aires: La Rocca, 1998.

KUTNER, Luis. The living will: a proposal. Indiana: Law Journal. 1969.

KVITKO, Luis Alberto. El consentimiento informado. Ciudadela: Dosyuna, 2009.

LALANDE, André. Vocabulário técnico e crítico da filosofia. $3^{\mathrm{a}}$ edição, São Paulo: Martins Fontes, 1999.

LARENS, Karl. Derecho justo - fundamentos de ética jurídica, tradução de Luiz DíezPicazo. Madrid: Civitas, 2001.

LIMA, Mônica M., Co-infecção HIV/tuberculose: necessidade de uma vigilância mais efetiva. Revista Saúde Pública, 31(3): 217-20, 1997.

LISBOA, Roberto Senise. Da confiança como valor fundamental e princípio geral do negocio jurídico. Tese para concurso público de provimento ao cargo de Professor Titular do Departamento de Direito Civil da FADUSP, 2008.

LLOBET I AGUADO, Josep. El deber de información en la formación de los contratos. Madrid: Marcial Pons, 1996.

LÔBO, Paulo Luiz Netto. Teoria geral das obrigações. São Paulo: Saraiva, 2005.

Responsabilidade civil dos profissionais liberais e o ônus da prova, in Doutrinas Essenciais, responsabilidade Civil, direito Fundamental à Saúde, coord.: NERY JUNIOR, Nelson et NERY, Rosa Maria de Andrade. São Paulo: Revista dos Tribunais, 2010 .

LOPEZ, Teresa Ancona. Exercício do direito e suas limitações: abuso do direito, in Responsabilidade civil: estudos em homenagem ao professor Rui Geraldo Camargo Viana, coord.: NERY, Rosa Maria de Andrade et DONNINI, Rogério. São Paulo: Revista dos Tribunais, 2009.

. O dano estético. $3^{\text {a }}$ edição, São Paulo: Revista dos Tribunais, 2004.

Princípio da precaução e evolução da responsabilidade civil. São Paulo: Quartier Latim, 2010.

LORENZETTI, Ricardo Luis. Fundamentos do Direito Privado, tradução de Vera Maria Jacob de Fradera. São Paulo: Revista dos Tribunais, 1998. 
Responsabilidad Civil de los Médicos, Tomos I e II. Buenos Aires: Rubinzal Culzoni, 1997.

LOTUFO, Renan et MARTINS, Fernando Rodrigues. 20 anos do código de defesa do consumidor: conquistas, desafíos e perspectivas. São Paulo: Saraiva, 2011.

LUELMO, Andrés Domínguez. Derecho sanitario y responsabilidad médica: Comentarios a la Ley 41/2002, de 14 de noviembre, sobre derechos Del paciente, información y documentación clínica. $2^{\text {a }}$ edição, Valladolid: Lex Nova, 2007.

MANAİ, Dominique et alie. Risques et informations dans le suivi de la grossesse: droit, éthique et pratiques sociales. Berne: Stämpfli et Bruylant, 2010.

MARIONI, Luiz Guilherme. Prova. São Paulo: Revista dos Tribunais, 2009.

MARMELSTEIN, George. Curso de Direitos Fundamentais. São Paulo: Atlas, 2008.

MARQUES, Claudia Lima, A responsabilidade dos médicos e do hospital por falha no dever de informar ao consumidor. São Paulo: Revista dos Tribunais, 2004.

Confiança no comércio eletrônico e a proteção do consumidor: um estudo dos negócios jurídicos de consumo no comércio eletrônico. São Paulo: Revista dos Tribunais, 2004.

Contratos no código de defesa do consumidor. $5^{a}$ edição, São Paulo: Revista dos Tribunais, 2006.

MARTINS-COSTA, Judith. A boa-fé no direito privado. São Paulo: Revista dos Tribunais, 1999.

. As interfaces entre a bioética e o direito, in Bioética, Organiz.: Joaquim Clotet. Porto Alegre: EDIPUCRS, 2001.

et ÁVILA, Humberto. Almiro do Couto e Silva e a Re-Significação do Princípio na relação entre o Estado e os Cidadãos, in Fundamentos do Estado de Direito - um estudo em homenagem ao Professor Almiro do Couto e Silva. São Paulo: Malheiros, 2005.

MARZAGÃO, Nelcina C. de Oliveira Tropardi. Da informação e dos efeitos do excesso de informação no direito do consumidor, Tese de doutoramento na Faculdade de Direito da Universidade de São Paulo, 2005.

MELLO, Celso Antônio Bandeira de. Curso de Direito Administrativo, 19ª Edição. São Paulo: Malheiros Editores, 2005.

MENEZES CORDEIRO, António Manuel da Rocha E. Da boa fé no direito civil. Coimbra: Almedina, 2001.

MIGLIORE, Alfredo Domingues Barbosa. Direito além da vida. São Paulo: LTr, 2009. 
MIRAGEM, Bruno. Curso de direito do consumidor. $2^{a}$ edição, São Paulo: Revista dos Tribunais, 2010.

MORAES, Maria Celina Bodin de. Danos à pessoa humana. Rio de Janeiro: Renovar, 2003. 2010. Na medida da pessoa humana: estudos de direito civil. Rio de janeiro: Renovar,

MORÁN, Luis González. La falta de información y consentimiento informado genera indemnización? in Los avances del derecho ante los avances de la medicina, coord.: GILDELGADO, Maria Reyes Corripio et COPO, Abel B. Veiga. Cizur Menor: Aranzadi, 2008.

MOTA PINTO, Carlos Alberto da. Teoria geral do direito civil. $4^{\text {a }}$ edição, por MONTEIRO, António Pinto et PINTO, Paulo Mota. Coimbra: Coimbra Editora, 2005.

MUÑOZ, Daniel Romero et FORTES, Paulo Antonio Carvalho. O princípio da autonomia e o consentimento livre e esclarecido, in Iniciação à bioética, Coord.: FERREIRA, Sergio Ibiapina et alii. Brasília: CFM, 1998.

NORONHA, Fernando. Direito das Obrigações. $3^{\text {a }}$ edição, São Paulo: Saraiva, 2010.

OLIVEIRA, Guilherme de. Temas de direito da medicina. $2^{\mathrm{a}}$ edição, Coimbra: Coimbra Editora, 2005.

ORBÁN, Carmen Blas. El equilibrio en La relación médico paciente. Barcelona: Bosch Editor, 2006.

OTERO, Paulo. Pessoa humana e constituição: contributo para uma concepção personalista do Direito Constitucional, in Pessoa humana e direito. Coord.: CAMPOS, Diogo Leite et CHINELLATO, Silmara Juny de Abreu. Coimbra: Almedina, 2009.

PEREIRA, André Gonçalo Dias. O consentimento informado na relação médico paciente Estudos de Direito Civil. Coimbra: Coimbra Editora, 2004.

PEREIRA, Caio Mário da Silva. Instituições de Direito Civil, volume I. 23 edição, Rio de Janeiro: Forense, 2010.

PIERRE, Philipe. La réparation du manquement à l'information médicale: d'une indemnisation corporalisée à la mise en oeuvre d'un droit créance. in Médicine \& Droit 2011 (2011), Elsevier Masson France, 2011, in www.sciencedirect.com.

PLATÃO. As leis, incluindo Epinomis. $2^{\mathrm{a}}$ edição, tradução e notas de Edson Bini. São Paulo: Edipro, 2010.

PONTES DE MIRANDA, Francisco C. Tratado de Direito Privado. $2^{\text {a }}$ edição, Rio de Janeiro: Borsoi, 1966. 
RAGAZZO, Carlos Emmanuel Joppert. $O$ dever de informar dos médicos e o consentimento informado. Curitiba: Juruá, 2006.

REBECQUE, Henri-Benjamin Constant de. On the liberty of the ancients comparend with that of the moderns, in Political Writings. Cambridge: Cambridge University Press, 1988.

RIBOT, Jordi. Consentimiento informado y responsabilidad civil médica em la reciente jurisprudencia del Tribunal español, in Lex Medicinae Revista Portuguesa de Direito da Saúde, ano 2, nº 3, janeiro/julho de 2005.

RIESTRA, Sergio Gallego. el derecho del paciente a la autonomia personal y las instrucciones previas: uma nueva realidad legal. Navarra: Aranzadi, 2009.

RODRIGUES, João Vaz. Consentimento informado para o acto médico no Ordenamento Jurídico Português - Elementos para o estudo da manifestação da vontade do paciente. Coimbra: Coimbra Editora, 2001.

RUGGIERO, Roberto de. Instituições de direito civil, vol I, tradução da $6^{\text {a }}$ edição italiana por Ary dos Santos.São Paulo: Sataiva, 1957.

ROUSSEAU, Jean-Jacques. O contrato social. São Paulo: Nova Cultural, 1997.

SANDERS, Lisa, Todo paciente tem uma história para contar. Rio de Janeiro: Jorge Zahar, 2010.

SANSEVERINO, Paulo de Tarso Vieira. Responsabilidade civil no código do consumidor e a defesa do fornecedor. $2^{\mathrm{a}}$ edição, São Paulo: Saraiva, 2007.

SARLET, Ingo Wolfgang. Algumas considerações em torno do conteúdo, eficácia e efetividade do direito à saúde na constituição de 1988, in Interesse Público $\mathrm{n}^{\circ} 12$, São Paulo, 2001.

Dignidade da pessoa humana e direitos fundamentais na constituição federal de 1988. $2^{a}$ edição, Porto Alegre: Livraria do Advogado, 2002.

SARMIENTO, Daniel. Direitos fundamentais e relações privadas. $2^{\text {a }}$ edição, Rio de Janeiro: Lumen Juris, 2008.

SCAFF, Fernando Campos. Direito à saúde no âmbito privado. São Paulo: Saraiva, 2010.

SCHREIBER, Anderson. A proibição de comportamento contraditório - tutela da confiança e venire contra factum proprium. $2^{\mathrm{a}}$ edição, Rio de Janeiro: Renovar, 2007.

. Direitos de Personalidade. São Paulo: Atlas, 2011.

SILVA, José Afonso. Curso de Direito Constitucional Positivo. $14^{\mathrm{a}}$ edição, São Paulo: Malheiros, 1997.

SILVA, Virgílio Afonso da. A constitucionalização do direito. São Paulo: Malheiros, 2008. 
STANCIOLI, Brunello. Renúncia ao exercício de direitos de personalidade. Belo Horizonte: Del Rey, 2010.

SZTAJN, Rachel. A responsabilidade civil do médico: visão bioética, in Revista de Direito Mercantil industrial, econômico e financeiro. São Paulo: Malheiros, 1997.

et MARCHI, Maria Mathilde, Autonomia e heteronomia na relação entre profissional de saúde e usuário dos serviços de saúde. in http://www.portalmedico.org.br/revista/bio1v6/autoheter.htm.

TEIXEIRA, Ana Carolina Brochado. Saúde, corpo e autonomia privada. Rio de Janeiro: Renovar, 2010.

TEPEDINO, Gustavo. A responsabilidade médica na experiência brasileira contemporânea, in Temas de Direito Civil, tomo II. Rio de Janeiro: Editora Renovar, 2006.

O direito civil-constitucional e suas perspectivas atuais, in Direito civil contemporâneo: novos problemas à luz da legalidade constitucional. São Paulo: Atlas, 2008 .

TOMASETTI JR., Alcides. $O$ objetivo de transparência e o regime jurídico dos deveres e riscos de informação nas declarações negociais para consumo, in Revista de direito do consumidor, volume 4, São Paulo: Revista dos Tribunais, 1992.

TOURNEAU, Philippe LE. Droit de la responsabilité et des contrats. $6^{\mathrm{a}}$ edição, Paris: Dalloz, 2006.

TROPARDI, Nelcina C. de Oliveira. Da informação e dos efeitos do excesso de informação no direito do consumdidor. Tese de doutoramente apresentada à Faculdade de direito da USP em 2005.

URRUTIA, Amílcar R. Responsabilidad civil por mala praxis quirúrgica. Buenos Aires: Hammurabi, 2010.

VALLESPINOS, Carlos Gustavo et OSSOLA, Federico Alejandro. La Obligación de informar el los contratos. Beunos Aires: Hammurabi, 2010.

VÁZQUEZ FERREYRA, Roberto. Daños y perjuicios en el ejercicio de la medicina. $2^{\mathrm{a}}$ edição, Buenos Aires: Hammurabi, 2002.

Derecho médico y mala práxis. Rosário: Editorial Júris, 2000.

http://www.sideme.org/doctrina/articulos/ci-ravf.pdf.

VERGALLO, Gianluca Montanari. Il rapporto medico-paziente. Milano: Giuffrè, 2008.

VIEIRA, Oscar Vilhena, A Constituição e sua Reserva de Justiça. São Paulo: Malheiros, 2002. 
Direitos fundamentais: uma leitura da jurisprudência do STF. São Paulo: Malheiros, 2006.

WEINGARTEN, Celia. Contrato y Responsabilidad Medica. El deber de informacion y el consentimiento informado (una visión crítica), in Relación Médico-paciente, Problemática Moderna. Coord.: GHERSI, Carlos A. $2^{a}$ edição, Mendonza: Jurídicas cuyo, 2000.

WHITE, Becky Cox. Competence to consent. Washington D.C: Georgetown University Press, 2007.

YERGA, Álvaro Luna. La prueba de la responsabilidad civil médico-sanitaria. Madrid: Civitas, 2004.

ZAPLANA, José Guerrero. Las reclamaciones por la defectuosa asistencia sanitaria: doctrina, jurisprudencia, legislación y formularios. $5^{\text {a }}$ edição, Valladolid: Lex Nova, 2006.

ZATZ, Mayana. Genética - escolhas que nossos avós não faziam. São Paulo: Globo, 2011.

ZULIANI, Ênio Santarelli. Inversão do ônus da prova na ação de responsabilidade civil fundada em erro médico, in Doutrinas Essenciais, Responsabilidade Civil, Direito Fundamental à Saúde, coord.: NERY JUNIOR, Nelson et NERY, Rosa Maria de Andrade. São Paulo: Revista dos Tribunais, 2010.

et BRUNHARI, Andréa de Almeida. O consumidor e seus direitos diante de erros médicos e falhas de serviços hospitalares, in Revista do advogado da Associação dos Advogados de São Paulo (20 anos de vigência do Código de Defesa do Consumidor desafios atuais), ano XXXI, $n^{\circ} 114$, dezembro de 2011. 


\section{OBRAS CONSULTADAS}

ALEXY, Robert. Teoria dos direitos fundamentais, tradução de Virgílio Afonso da Silva. São Paulo: Malheiros, 2006.

ASCENSÃO, José de Oliveira. Estudos de direito da bioética, in Associação Portuguesa de Direito Intelectual. Coimbra: Edições Almedina, 2009.

BOBBIO, Norberto. A era dos direitos, tradução de Carlos Nelson Coutinho. Rio de Janeiro: Elsevier, 2004.

CALABRESI, Guido et BOBBITT, Philip. Tragic choices: the conflicts society confronts in the allocation of tragically scarce resources. New York: W. W. Norton \& Company, 1978.

CANOTILHO, José Joaquim Gomes. Direito constitucional. $7^{\mathrm{a}}$ edição, Coimbra: Almedina, 2003.

CIFUENTES, Santos. Derechos personalíssimos. $3^{\mathrm{a}}$ edição, Buenos Aires: Editorial Astrea, 2008.

DINIZ, Maria Helena. O estado atual do biodireito. São Paulo: Saraiva, 2001.

DONNINI, Rogério Ferraz. Responsabilidade pós-contratual no novo código civil e no código de defesa do consumidor. São Paulo: Saraiva, 2004.

FACHIN, Luiz Edson et RUZIK, Carlos Eduardo Pianovski. Direitos fundamentais, dignidade da pessoa humana e o novo código civil: uma análise crítica, in Constituição, direitos fundamentais e direito privado. $2^{\mathrm{a}}$ edição, Porto Alegre: Livraria do Advogado, 2006.

FERRAZ JUNIOR, Tercio Sampaio. Direito constitucional: liberdade de fumar, privacidade, estado, direitos humanos e outros temas. São Paulo: Manole, 2007.

FOUCAULT, Michel. O nascimento da clínica. $6^{\mathrm{a}}$ edição, tradução de Roberto Machado, Rio de Janeiro: Forense Universitária, 2008.

GADAMER, Hans-Georg. O caráter oculto da saúde. Rio de Janeiro:Vozes, 2006.

GHERSI, Carlos Alberto Problemática moderna, relación médico-paciente. Buenos Aires: Ediciones Jurídicas Cuyo, 2000.

GONZÁLEZ, Matilde Zavala de. Resarcimiento del daño moral. Buenos Aires: Editorial Astrea, 2009.

HABERMAS, Jürgen. Técnica e ciência como “ideologia”. Lisboa: Edições 70, 2006.

JONAS, Hans. Ténica, medicia y ética: la práctica del princípio de responsabilidad. Barcelona: Paidós Básica, 1997. 
MESSINEO, Francesco. Doctrina general del contrato, tradução de R. O. Fontanarrosa. Lima: Ara Editores, 2007.

NERY, Rosa Maria de Andrade. Introdução ao pensamento jurídico e à teoria geral do direito privado. São Paulo: Revista dos Tribunais, 2008.

NORONHA, Fernando. O direito dos contratos e seus princípios fundamentais: autonomia privada, boa-fé, justiça contratual. São Paulo: Saraiva, 1994.

OSELKA, Gabriel. Bioética clínica: reflexões e discussões sobre casos selecionados. São Paulo: CREMESP, 2008.

RODOTÀ, Stefano. La vida y las reglas: entre el derecho y el no derecho, tradução de Andrea Greppi. Madrid: Trotta, 2010.

ROPPO, Vincenzo. Il contratto. Milano: Dott. A. Giuffrè, 2001.

SILVA, Regina Beatriz Tavares da. Responsabilidade civil na área da saúde. São Paulo: Saraiva, 2007.

Responsabilidade civil nas relações de consumo. São Paulo: Saraiva, 2009.

VISINTINI, Giovanna, Cos'è la responsabilità civile. Napoli: Edizione Scientifiche Italiane, 2009.

Trattato breve della responsabilità civile. Napoli: CEDAM, 2005.

WELSCH, Sylvie. Responsabilité du Médicin. Paris: Litec, 2003. 